\title{
A Floristic Research on Karatepe-Aslantaş National Park and Some Protected Natural/Cultural Areas (Osmaniye, Türkiye)
}

\author{
Ahmet Zafer TEL ${ }^{1,2}$, İshak ORTAÇ3* ${ }^{*}$ Ahmet İLÇiM ${ }^{4}$ \\ ${ }^{1}$ Department of Biology, Faculty of Science and Letters, Adiyaman University, Adiyaman, Turkey \\ ${ }^{2}$ Department of Agricultural Biotechnology, Faculty of Agriculture, I $\breve{g} d \imath r$ University, I $\breve{g} d \imath r$, Turkey \\ ${ }^{3}$ Department of Biology, Institute of Science, Adiyaman University, Adiyaman, Turkey \\ ${ }^{4}$ Department of Biology, Faculty of Arts and Science, Mustafa Kemal University, Hatay, Turkey
} ORCID ID: Ahmet ZaferTEL: https:/ / orcid.org/0000-0002-1204-3839; İshak ORTAÇ: https:/ / orcid.org/0000-0002-5880-8438; AhmetiLÇİM: https://orcid.org/0000-0001-8169-2472

\begin{abstract}
$\begin{array}{llll}\text { Received: 01.11.2019 } & \text { Accepted: 18.12.2019 } & \text { Published online: 20.12.2019 } & \text { Issue published: 20.12.2019 }\end{array}$
Abstract: Research areas are the National Park of Karatepe-Aslantaş, Harun Reşit Castle, Haruniye Springs, and Şarlak Falls located in Osmaniye, Turkey. This study was conducted between 2015 and 2016. As a result of this study, 164 taxa belonging to 59 families, 139 genera, 135 species, 23 subspecies, and 6 varieties were determined. Fifteen taxa identified in the study area were endemic and the rate of endemism was $9.1 \%$. The distribution of taxa in phytogeographic regions in the research area is as follows: Mediterranean (including the Eastern Mediterranean) 63 taxa (38.4\%), Euro-Siberian 10 taxa (6.1\%), Irano-Turanian 7 taxa (4.3\%), 39 widespread taxa (23.8\%) and 45 unknown taxa (27.4\%). Fabaceae (26), Asteraceae (13), Lamiaceae (13), Brassicaceae (7), and Rosaceae (7) are the largest families in terms of the number of taxa in the research area. Securigera DC. (3), Centaurea L. (3), Quercus L. (3), and Salvia L. (3) are the largest genera in terms of the number of taxa in the research area.

Keywords: Protected environments, plant diversity, taxonomic records, Mediterranean, Anatolia.
\end{abstract}

\section{Karatepe-Aslantaş Milli Parkı ve Bazı Doğal/Kültürel Koruma Alanları Üzerine Floristik Bir Araştırma (Osmaniye, Türkiye)}

\begin{abstract}
Öz: Araştırma alanları Osmaniye (Türkiye) ilinde bulunan Karatepe-Aslantaş Milli Parkı, Harun Reşit Kalesi, Haruniye Kaplıcaları ve Şarlak Şelalesidir. Bu çalışma 2015-2016 yılları arasında yapılmıştır. Çalışma sonucunda 59 familyaya ait 139 cins, 135 tür, 23 alttür ve 6 varyete olmak üzere toplam 164 takson tespit edilmiştir. Çalışma alanında tespit edilen taksonlardan 15 tanesi endemik olup, endemizm oranı \%9.1'dir. Araştırma alanında taksonların fitocoğrafik bölgelere dağılımı şöyledir: Akdeniz (Doğu Akdeniz dâhil) 63 takson (\%38.4), Avrupa-Sibirya 10 takson (\%6.1), İran-Turan 7 takson (\%4.3), Geniş yayılışlı 39 takson (\%23.8) ve bilinmeyen 45 (\%27.4) taksondur. Araştırma alanında takson sayısı bakımından en büyük familyalar Fabaceae (26), Asteraceae (13), Lamiaceae (13), Brassicaceae (7) ve Rosaceae (7)'dir. Araştırma alanında takson sayısı bakımından en büyük cinsler Securigera DC. (3), Centaurea L. (3), Quercus L. (3) ve Salvia L. (3)'dır.
\end{abstract}

Anahtar kelimeler: Korunan ortamlar, bitki çeşitliliği, taksonomik kayıtlar, Akdeniz, Anadolu.

\section{Giriş}

Türkiye, bitki çeşitliliği konusunda oldukça zengin ve özel bir konuma sahiptir. Coğrafik konumu, fitocoğrafik özellikleri, klimatik ve edafik çeşitliliği nedeniyle, barındırdığı endemik türler bakımından dünyanın sayılı ülkeleri arasında yer almaktadır (Davis \& Hedge, 1975).

Çalışma alanlarımızın içerisinde yer aldı ğ 1 Osmaniye ili, bitki coğrafyası açısından holoarktik flora alemi içerisinde olup, Doğu Akdeniz bölümünde bulunmaktadır. Jeobotanik açıdan bölgemiz Akdeniz sert yapraklı ormanları olarak tanımlanmıştır. Bölgemizde dikey yönde üç farklı vejetasyon kuşağı yer almaktadır. Bunlar; maki, orman ve orman üstü kuşaklarından oluşmaktadır (Çevre ve Şehircilik Bakanlığı, 2016; Ortaç, 2017).

Araştırma alanına yakın bölgelerde benzer florostik çalışmalar yapılmıştır. Bu çalışmalar; Altınözlü (2004) Adana Yumurtalık Lagünü'nden 65 familyaya ait 186 cins, 234 takson tespit etmiştir. Tespit edilen taksonlardan 3 tanesi endemik olup endemizm oranı \%3.1'dir. Kavak (2006) Burnaz Kumulları'ndan 45 familyaya ait 147 cins, 229 takson tespit etmiştir. Tespit edilen taksonlardan 7 tanesi endemik olup endemizm oranı \%3.05'dir. Akıncı
(2010), Akdağ ve Çevresi'nden 88 familyaya ait, 362 cins ve 739 takson tespit etmiştir. Tespit edilen taksonlardan 100 tanesi endemik olup endemizm oranı \%13.6'dır. Paksoy ve Savran (2011), Sarımsak dağ1 ve Korkun Vadisi'nden 78 familyaya ait 315 cins ve 652 takson tespit etmiştir. Tespit edilen taksonlardan 135 tanesi endemik olup endemizm oranı \%20.7'dir. Tatarlı Höyük'ünden, 38 familyaya ait 110 cins ve 149 takson tespit edilmiştir. Tespit edilen taksonlardan 3 tanesi endemik olup endemizm oranı \%2'dir (Kavak, Talip, Aslan, Çakan, \& Umut, 2012). Keskin (2014), Kızıldağ Yayla ve Çevresi'nden 75 familyaya ait 285 cins ve 574 takson tespit etmiştir. Tespit edilen taksonlardan 97 tanesi endemik olup endemizm oranı \%16.8'dir. Tübives (Türkiye Bitkileri Veri Servisi) verilerine göre Osmaniye ilinin tamaminda toplam 443 takson tespit edilmiştir (Orman ve Su İşleri Bakanlığı, 2013). Tespit edilen bu taksonlardan 108 tanesi endemik olup endemizm oranı \%24.3'dür.

$\mathrm{Bu}$ araştırmada Osmaniye ilinde bulunan KaratepeAslantaş Milli Parkı, Harun Reşit Kalesi, Haruniye Kaplıcaları ve Şarlak Şelalesi florası üzerine bir envanter çalışması yapmak, bu alanlarda ve Osmaniye ilinde yapılacak diğer araştırmalara katkı sağlamak amaçlanmıştır. 


\section{Materyal ve Yöntem}

Çalışma alanının materyalini 2015-2016 yılları arasında Osmaniye ilinde bulunan Karatepe-Aslantaş Milli Parkı, Harun Reşit Kalesi, Haruniye Kaplıcaları ve Şarlak Şelalesi çevresinden toplanan bitki örnekleri oluşturmaktadır. Çalışma alanlarına farklı vejetasyon dönemlerinde gidilmiş, toplanan bitki örnekleri herbaryum materyali olarak muhafaza edilmeye uygun olacak biçimde kurutulmuş ve preslenmiştir. Etiket bilgisi için gerekli notlar (adres, habitat, tarih vs.) alınmış ve toplanan bitki örnekleri herbaryum materyali haline getirilmiştir. Toplanan bitki örneklerinin teşhisi temel kaynaklardan (Davis, 1965-1985; Davis, Mill, \& Tan, 1988; Güner, Özhatay, Ekim, \& Başer, 2000) yararlanılarak yapılmıştır. Bitki örnekleri Hatay Mustafa Kemal Üniversitesi Herbaryumunda saklanmaktadır. Tespit edilen bitki örneklerinin tehlike kategorileri ve Türkçe isimleri yazılmıştır (Vural, 2006; Güner, Aslan, Ekim, Vural, \& Babaç, 2012).

Araştırma alanlarının florasını meydana getiren taksonlar ile Tübives (Türkiye Bitkileri Veri Servisi) verilerinde yer alan taksonlardan aynı olanları (*) işareti ile işaretlenmiştir. Taksonların ait oldukları güncel familyalar, alfabetik sıraya göre listelenmiştir. Tespit edilen taksonlar; listede sirasiyla; familya ismi, güncel bilimsel adı, fitocoğrafik bölgesi, endemizm durumu/tehlike kategorisi ve Türkçe adı şeklinde verilmiştir. Örnek toplanan adresler numaralarla gösterilmiştir. Bu adresler: 1: Harun Reşit Kalesi, 2: Haruniye Kaplıcaları, 3: Karatepe-Aslantaş Milli Parkı, 4: Şarlak Şelalesi'dir (Tablo 1).

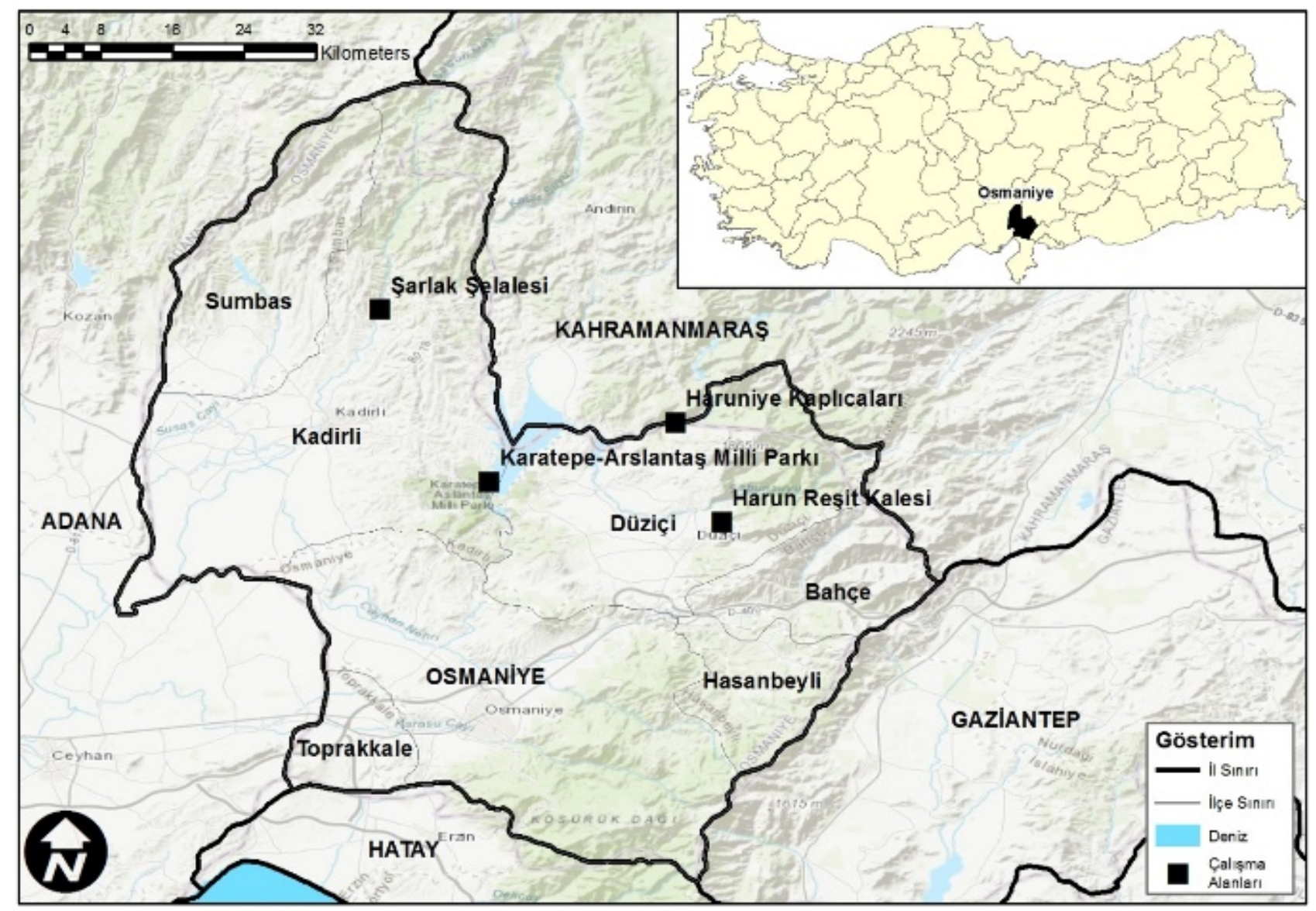

Şekil 1. Araştırma alanlarının konumu.

\section{Bulgular}

Çalışma alanlarının tamamı Osmaniye ilinde ve Davis (1965-1985)'in kullandığ1 grid sistemine göre "C6" karesinde yer almaktadır. Harun Reşit Kalesi ve Haruniye kaplıcaları Düziçi İlçesinde, Karatepe-Aslantaş Milli Parkı Düziçi-Kadirli ve Şarlak Şelalesi Sumbas-Kadirli İlçeleri arasında bulunur (Şekil 1).

Harun Reşit Kalesi kalker kayalıklardan oluşan bir tepe üzerine kurulmuştur. Alandaki bitki örtüsü tipik maki elemanlarından oluşmaktadır. Haruniye Kaplıcaları Ceyhan nehir yatağı kıyısında bulunmaktadır. Alanın bir kenarı dere vejetasyonu özelliği göstermektedir. Diğer kısımlar konifer orman ve maki elemanlarından oluşmaktadır. Karatepe-Aslantaş Milli Parkı baraj kenarında olup, sucul ve konifer orman habitatının hâkim olduğu peyzaj değeri yüksek bir alandır. Şarlak şelalesi ise, Kesiksuyu çayı üzerinde bulunmaktadır. Araştırma kapsamina giren bu alanlarda genel olarak kaya, sucul ve konifer orman vejetasyonu gözlenir (Çevre ve Şehircilik Bakanlı̆̆ı, 2016).

Osmaniye ili yıllık sıcaklık ortalaması $18.4^{\circ} \mathrm{C}^{\prime}$ dir. Ortalama sicaklıklar bakımından en soğuk ay $8.6^{\circ} \mathrm{C}$ ile ocak, en sıcak ay ise $28.5^{\circ} \mathrm{C}$ ile ağustostur. En sicak ve en soğuk ay arasında $19.9^{\circ} \mathrm{C}^{\prime}$ lik fark vardır. Araştırma alanlarında ortalama yıllık yağış miktarı $827.6 \mathrm{~mm}$ 'dir. En fazla yağış $120.5 \mathrm{~mm}$ ile mart ayında, en az yağış ise 5.7 mm ile ağustos ayında ölçülmüştür. En fazla ve en az yağış arasında $114.8 \mathrm{~mm}$ fark vardır. Mevsimsel olarak yıllık toplam yağışın \%36.2'sinin kışın, \%33.6'sının ilkbahar, \%23.9'unun sonbahar ve \%6.3'ünün de yazın düştüğü rapor edilmiştir (Meteoroloji Genel Müdürlüğü, 2019). 
Araştırma alanının iklim diyagramı Meteoroloji Genel Müdürlüğü (2019)'nden elde edilen 1981-2010 yılları arasındaki verilere göre hazırlanılmıştır (Şekil 2).

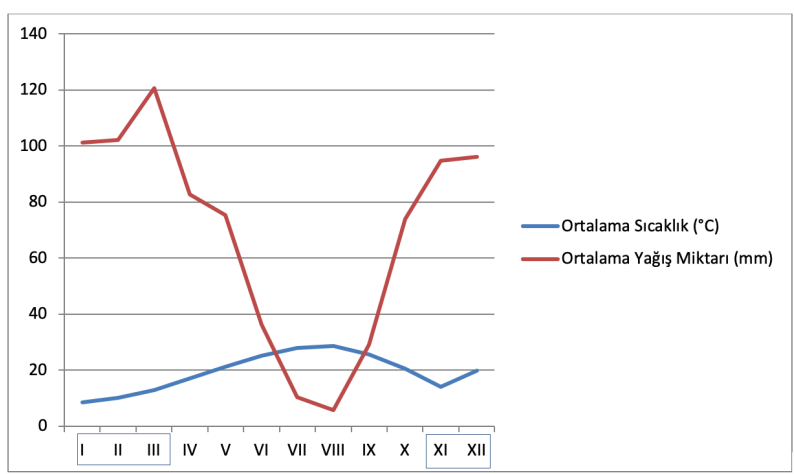

Şekil 2. Osmaniye ilinin iklim diyagramı (Meteoroloji Genel Müdürlüğü, 2019).

\section{Tartışma}

Araştırma alanlarından toplanan bitkilerin teşhisi sonucu; 59 familya ve 139 cinse ait toplam 135 tür, 23 alttür ve 6 varyete olmak üzere toplam 164 takson tespit edilmiştir.
Tespit edilen bu taksonlardan $15^{\prime} \mathrm{i}$ endemik olup, araştırılan alanların endemizm oranı \%9.1'dir. Araştırma alanında tanımlanan taksonlardan 30 tanesi Tübives verilerinde yer alan taksonlarla ayn olup 134 tanesi farklıdır. Çakışan 30 taksondan 7 tanesi endemik olup 8 tanesi ise farklıdır. Tespit edilen taksonların fitocoğrafik bölgelere dağılımı şöyledir: Akdeniz (Doğu Akdeniz dahil) 63 takson (\%38.4), Avrupa-Sibirya 10 takson (\%6.1), İran-Turan 7 takson (\%4.3), Geniş yayılışlı 39 takson (\%23.8) ve bilinmeyen 45 (\%27.4) takson (Tablo 2). Akdeniz fitocoğrafik bölge elementi olan taksonların fazlalığı, araştırma alanlarının tamamının bu bölgede olmasının doğal bir sonucu olarak değerlendirilmiștir (Tablo 2).

Araştırma alanında tespit edilen 15 endemik taksondan 11'i Akdeniz ve 2'si İran-Turan fitocoğrafik bölge elementidir. 2 taksonun ise fitocoğrafik bölgesi belli değildir. Tespit edilen endemik taksonlar, dâhil edildikleri tehlike kategorileri bakımından gruplandırıldığında; 1 taksonun CR (kritik), 1 taksonun VU (zarar görebilir), 6 taksonun NT (tehdit altına girebilir) ve 7 taksonun LC (en az endişe verici) kategorisinde olduğu tespit edilmiştir (Vural, 2006).

Tablo 1. Araştırma alanında tespit edilen bitki listesi

\begin{tabular}{|c|c|c|c|c|c|}
\hline Familya & Bilimsel Ad & Fitocoğrafik Bölge & $\begin{array}{c}\text { Endemizm } \\
\text { /Tehlike } \\
\text { kategorisi }\end{array}$ & Türkçe Ad & Adres \\
\hline Adoxaceae & Sambucus ebulus L. & Avrupa-Sibirya Elementi & -1 & Mürver otu & 1,2 \\
\hline Amaryllidaceae & Allium neapolitanum Cirillo & Akdeniz Elementi & -1 & Sarımsak çiçeği & 3 \\
\hline \multirow{3}{*}{ Anacardiaceae } & Cotinus coggygria Scop. & - & -1 & Boyacı somağı (Sarı kök, Sarı odun) & 2,3 \\
\hline & Pistacia paleastina Boiss. & Doğu Akdeniz Elementi & -1 & Menengiç & $1,2,3,4$ \\
\hline & Rhus coriaria $\mathrm{L}$. & - & -1 & Somak & 1 \\
\hline \multirow[t]{2}{*}{ Apiaceae } & $\begin{array}{l}\text { Eryngium campestre L. var. virens (Link) } \\
\text { Weins }\end{array}$ & Geniş Yayılışlı & -1 & Yerkestanesi & 3 \\
\hline & E. falcatum F.Delaroche & Doğu Akdeniz Elementi & -1 & Çatal boğadikeni & 3,4 \\
\hline Apocynaceae & Nerium oleander $\mathrm{L}$. & Akdeniz Elementi & -1 & Zakkum & 2,4 \\
\hline Araliaceae & Hedera helix $\mathrm{L}$. & - & -1 & Duvar sarmaşığı & $1,2,3$ \\
\hline \multirow[t]{5}{*}{ Asparagaceae } & Asparagus acutifolius L. & Akdeniz Elementi & -1 & Tilkişen & $1,2,3,4$ \\
\hline & ${ }^{*}$ Muscari parviflorum Desf. & Akdeniz Elementi & -1 & Güz müşkürümü & 3 \\
\hline & M. babachii Eker \& Koyuncu & Akdeniz Elementi & $+/ \mathrm{CR}$ & Tekin Sümbülü & 1,2 \\
\hline & Prospera autumnale $\mathrm{L}$. & Akdeniz Elementi & $-/$ & Güz Sümbülü & 1,3 \\
\hline & ${ }^{*}$ Ruscus aculeatus L. & - & -1 & Tavşanmemesi & $1,2,3,4$ \\
\hline \multirow[t]{13}{*}{ Astereceae } & Bellis perennis L. & Avrupa-Sibirya Elementi & -1 & Koyungözüotu & $1,3,4$ \\
\hline & $\begin{array}{l}\text { Carduus pycnocephalus L. subsp. albidus } \\
\text { (M.Bieb.) Kazmi }\end{array}$ & Geniş Yayılışlı & -1 & Eşek soymacı & 1,4 \\
\hline & Centaurea iberica Trevir. ex Spreng. & Geniş Yayılışlı & -1 & Deligözdikeni & 4 \\
\hline & ${ }^{*}$ C. lycopifolia Boiss. \& Kotschy & Doğu Akdeniz Elementi & $+/ \mathrm{NT}$ & Cerrah Otu & $1,2,4$ \\
\hline & C. solstitialis L. subsp. solstitialis & Geniş Yayılışlı & $-/$ & Çakırdikeni & 2,4 \\
\hline & Cichorium intybus L. & Geniş Yayılışlı & -1 & Hindiba & 4 \\
\hline & ${ }^{*}$ Doronicum orientale Hoffm. & Geniş Yayılışlı & -1 & Kaplan otu & 1,3 \\
\hline & Echinops ritro $\mathrm{L}$. & - & -1 & Topuz & 3 \\
\hline & Inula viscosa (L.) Aiton & Akdeniz Elementi & -1 & Andizotu & $1,2,3$ \\
\hline & Notobasis syriaca (L.) Cass & Akdeniz Elementi & -1 & Yavan kenger & 4 \\
\hline & Picnomon acarna (L.) Cass. & Akdeniz Elementİ & -1 & Kılçık diken & 1 \\
\hline & Silybum marianum (L.) Gaertn. & Akdeniz Elementi & -1 & Devedikeni & 1 \\
\hline & Sonchus oleraceus L. & - & -1 & Eşek gevreği & 2 \\
\hline \multirow[t]{4}{*}{ Boraginaceae } & ${ }^{*}$ Alkanna kotschyana DC. & Doğu Akdeniz Elementi & $+/ \mathrm{LC}$ & Meşe havacivası & 3 \\
\hline & Cynoglossum creticum Mill. & - & -1 & Pisik tetiği & 1,3 \\
\hline & C. montanum $\mathrm{L}$. & Avrupa-Sibirya Elementi & -1 & Dağ köpekdili & 1 \\
\hline & Heliotropium europaeum L. & Akdeniz Elementi & -1 & Akrep otu & 1 \\
\hline \multirow[t]{7}{*}{ Brassicaceae } & Capsella bursa-pastoris (L.) Medik. & Geniş Yayılışlı & -1 & Çobançantası & 1 \\
\hline & $\begin{array}{l}\text { Fibigia clypeata (L.) Medik. subsp. clypeata } \\
\text { var. eriocarpa (DC.) Post }\end{array}$ & - & -1 & Sikkeotu & 1 \\
\hline & Nasturtium officinale R.Br. & Geniş Yayılışlı & -1 & Su teresi & 4 \\
\hline & $\begin{array}{l}\text { Neslia paniculata (L.) Desv. subsp. thracica } \\
\text { (Velen.) Bornm }\end{array}$ & Geniş Yayılışlı & -1 & Göçmenhardalı & 1,4 \\
\hline & $\begin{array}{l}\text { Raphanus raphanistrum L. subsp. } \\
\text { raphanistrum. }\end{array}$ & Geniş Yayılışlı & -1 & Eşek turpu & 1 \\
\hline & Sinapis arvensis L. & Geniş Yayılışlı & -1 & Hardal & 1 \\
\hline & Thlaspi cilicicum (Boiss.) Hayek & - & $+/ \mathrm{NT}$ & Şeytan dağarcığı & 1 \\
\hline
\end{tabular}




\begin{tabular}{|c|c|c|c|c|c|}
\hline Familya & Bilimsel Ad & Fitocoğrafik Bölge & $\begin{array}{l}\text { Endemizm } \\
\text { /Tehlike } \\
\text { kategorisi }\end{array}$ & Türkçe Ad & Adres \\
\hline \multirow[t]{3}{*}{ Campanulaceae } & ${ }^{*}$ Campanula rapunculoides Ls & Avrupa-Sibirya Elementi & $-/$ & Elmacık & 4 \\
\hline & ${ }^{*}$ C. strigosa Banks \& Sol. & Doğu Akdeniz Elementi & -1 & Kıraç çanı & 4 \\
\hline & ${ }^{*}$ Michauxia campanuloides L'Herit ex Aiton & Doğu Akdeniz Elementi & -1 & Keşir & 1 \\
\hline \multirow[t]{2}{*}{ Cannabaceae } & Celtis planchoniana K.L.Chr. & Geniş Yayılışlı & -1 & Dahum & 2,3 \\
\hline & Humulus lupulus L. & Avrupa-Sibirya Elementi & $-/$ & Şerbetçiotu & 1 \\
\hline Capparaceae & Capparis spinosa L.a & - & -1 & Kebere & 2 \\
\hline \multirow[t]{2}{*}{ Caprifoliaceae } & Cephalaria taurica Szabo & - & $+/ \mathrm{VU}$ & Kırım pelemiri & 1,2 \\
\hline & Scabiosa rotata M.Bieb. & İran-Turan Elementi & $-/$ & Top uyuzotu & 1 \\
\hline \multirow[t]{3}{*}{ Caryophyllaceae } & ${ }^{*}$ Dianthus zonatus Fenzl var. zonatus & - & $-/$ & Kaya karanfili & 1 \\
\hline & Silene colorata Poir. & - & -1 & Kum nakılı & 1 \\
\hline & S. viscosa (L.) Pers. & - & -1 & Konya gıvışkanı & 2 \\
\hline \multirow[t]{3}{*}{ Cistaceae } & Cistus creticus L. & Akdeniz Elementi & -1 & Laden & $1,2,3$ \\
\hline & C. salviifolius L. & Geniş Yayılışlı & -1 & Kartli & 2,3 \\
\hline & $\begin{array}{l}\text { Helianthemum nummularium (L.) Mill. } \\
\text { subsp. nummularium }\end{array}$ & - & -1 & Güngülü & 1 \\
\hline Colchicaceae & ${ }^{*}$ Colchicum cilicicum (Boiss.) Dammer & Doğu Akdeniz Elementi & $-/$ & Ayıçiğdemi & 3 \\
\hline \multirow[t]{2}{*}{ Corylaceae } & Corylus avellana L. var. avellana & Avrupa Sibirya Elementi & $-/$ & Findik & 1 \\
\hline & Ostrya carpinifolia Scop. & Akdeniz Elementi & -1 & Firek & 1,4 \\
\hline Crassulaceae & Umbilicus luteus (Huds.) Webb \& Berthel. & - & -1 & Dik Göbek Otu & 2 \\
\hline Cupressaceae & Juniperus oxycedrus L. subsp. oxycedrus & Geniş Yayıllışlı & -1 & KatranArdicı & 1 \\
\hline Datiscaceae & Datisca cannabina $\mathrm{L}$. & - & -1 & Renk otu & $2,3,4$ \\
\hline Dennstaedtiaceae & Pteridium aquilinum (L.) Kuhn. & - & $-/$ & Eğrelti & 2 \\
\hline Elaeagnaceae & Elaeagnus angustifolia $\mathrm{L}$. & Geniş Yayılışlı & -1 & İğde & 3 \\
\hline \multirow[t]{3}{*}{ Ericaceae } & *Arbutus andrachne L. & - & -1 & Sandal ağacı & 2 \\
\hline & A. unedo L. & - & $-/$ & Kocayemiş & 3,4 \\
\hline & Erica manipuliflora Salisb. & Doğu Akdeniz Elementi & -1 & Püren & 3 \\
\hline \multirow[t]{2}{*}{ Euphorbiaceae } & Euphorbia helioscopia L. & Geniş Yayılışlı & -1 & Feriban otu & 1 \\
\hline & E. aleppica L. & Geniş Yayılışlı & -1 & Haşul & 2 \\
\hline \multirow[t]{26}{*}{ Fabaceae } & Astragalus hamosus L. & - & -1 & Koçboynuzu & 3 \\
\hline & ${ }^{*}$ A. schizopterus Boiss. & Doğu Akdeniz Elementi & -1 & Kedi çomağı & 1,4 \\
\hline & ${ }^{*}$ Calicitome villosa (Poiret) Link & Akdeniz Elementi & -1 & Keçi boğan & 3 \\
\hline & $\begin{array}{l}{ }^{*} \text { Cercis sliquastrum L. subsp. hebecarpa } \\
\text { (Bornm.) Yalt. }\end{array}$ & - & -1 & Zazalak & 3,4 \\
\hline & Colutea cilicica Boiss. \& Balansa & Geniş Yayılışlı & -1 & Patlangaç & 1,2 \\
\hline & Cytisus drepanolobus Boiss. & Doğu Akdeniz Elementi & $+/ \mathrm{NT}$ & Has kuşçubuğu & 3 \\
\hline & Dorycnium hirsutum (L.) Ser. & Akdeniz Elementi & -1 & Kıllı kaplanotu & 3 \\
\hline & $\begin{array}{l}{ }^{*} D \text {. pentaphyllum Scop. subsp. haussknechtii } \\
\text { (Boiss.) Gams }\end{array}$ & İran-Turan Elementi & $+/ \mathrm{LC}$ & Gervenük & 2,3 \\
\hline & $\begin{array}{l}\text { Genista januensis Boiss. subsp. lydia (Boiss.) } \\
\text { Kit Tan \& Ziel. }\end{array}$ & Doğu Akdeniz Elementi & -1 & Katırtırnağ1 & 3 \\
\hline & ${ }^{*}$ Glycyrrhiza flavescens Boiss. & Doğu Akdeniz Elementi & $+/ \mathrm{NT}$ & Sarı meyan & 3 \\
\hline & Hammatolobium lotoides Fenzl & Doğu Akdeniz Elementi & $-/$ & Alagazal boynuzu & 3 \\
\hline & $\begin{array}{l}\text { Hippocrepis emerus L. subsp. emeroides } \\
\text { (Boiss. \& Spruner) Lassen }\end{array}$ & - & $-/$ & Yalancı burçak & $1,2,3$ \\
\hline & Lathyrus aphaca L. var. biflorus Post & Geniş Yayılışlı & -1 & Mürdümük & 1,2 \\
\hline & $\begin{array}{l}\text { *Lathyrus variabilis (Boiss.\& Kotschy) } \\
\text { Čelak. }\end{array}$ & Doğu Akdeniz Elementi & -1 & Bayır burçağı & 3 \\
\hline & Lotus cytisoides L. & Akdeniz Elementi & $-/$ & Sepik tırfılı & 3 \\
\hline & Onobrychis gracilis Besser & - & -1 & Zarif korunga & 3 \\
\hline & $\begin{array}{l}\text { Pisum sativum L. subsp. elatius (M.Bieb.) } \\
\text { Aschers. \& Graebn var. elatius }\end{array}$ & Akdeniz Elementi & $-/$ & Boylu bezelye & 2 \\
\hline & Bituminaria bituminosa $\mathrm{L}$. & Akdeniz Elementi & $-/$ & Asfaltotu & 1,2 \\
\hline & Robinia pseudoacacia L. & - & -1 & Yalancı akasya & 1 \\
\hline & Securigera cretica ( L.) Lassen & Akdeniz Elementi & -1 & Yalancı otu & 1,3 \\
\hline & S. grandiflora Lassen & Doğu Akdeniz Elementi & $+/ \mathrm{LC}$ & Yalancı manolya & 1,2 \\
\hline & S. varia (L.) Lassen & Doğu Akdeniz Elementi & -1 & Taş Yoncası & 1 \\
\hline & Spartium junceum $\mathrm{L}$. & Akdeniz Elementi & -1 & Katır Tırnağı & 3,4 \\
\hline & Trifolium repens L. var. repens & - & $-/$ & Ak Üçgül & 3 \\
\hline & Vicia cracca L. subsp. stenophylla Vel. & Geniş Yayılışlı & -1 & Meşe fiği & 3 \\
\hline & V. hybrida L. & Geniş Yayılışlı & -1 & Melez bakla & 1 \\
\hline \multirow[t]{3}{*}{ Fagaceae } & Quercus brantii Lindley & İran-Turan Elementi & -1 & Kara meşe & 3 \\
\hline & Q. cerris L. & Akdeniz Elementi & -1 & Saçlı meşesi & $1,3,4$ \\
\hline & Q. coccifera L. & Akdeniz Elementi & -1 & Kermes meşesi & $1,2,3$ \\
\hline Gentianaceae & Centaurium pulchellum (Sw.) Druce & Geniş yayılışlı & -1 & Pembe Tukul & 2 \\
\hline \multirow[t]{2}{*}{ Geraniaceae } & Erodium gruinum L. & Doğu Akdeniz Elementi & -1 & Kargadıdağı & 4 \\
\hline & Geranium lucidum L. & - & -1 & Dakka otu & 1,4 \\
\hline \multirow[t]{2}{*}{ Hypericaceae } & Hypericum perfoliatum $\mathrm{L}$. & Akdeniz Elementi & -1 & Binbirdelikotu & $2,3,4$ \\
\hline & ${ }^{*}$ H. thymifolium Banks \& Sol. & Doğu Akdeniz Elementi & -1 & Çam kantaronu & 1 \\
\hline Iridaceae & Gladiolus italicus Mill. & - & -1 & Kılıç otu & 3 \\
\hline Juglandaceae & Juglans regia $\mathrm{L}$. & Geniş Yayılışlı & -1 & Ceviz & 1 \\
\hline Juncaceae & *Juncus inflexus L. & Geniş Yayılışlı & $-/$ & Sazak & 4 \\
\hline Lamiaceae & Ajuga orientalis L. & - & -1 & Dağ mayasılı & 1,4 \\
\hline
\end{tabular}




\begin{tabular}{|c|c|c|c|c|c|}
\hline Familya & Bilimsel Ad & Fitocoğrafik Bölge & $\begin{array}{l}\text { Endemizm } \\
\text { /Tehlike } \\
\text { kategorisi }\end{array}$ & Türkçe Ad & Adres \\
\hline & ${ }^{*}$ Lamium maculatum L. & Doğu Akdeniz Elementi & & Benlibalıcak & 1 \\
\hline & $\begin{array}{l}\text { Mentha longifolia (L.)Huds. subsp. typhoides } \\
\text { (Briq.) Harley }\end{array}$ & Geniş Yayılışlı & -1 & Dere nanesi & 4 \\
\hline & Micromeria myrtifolia Boiss. \& Hohen. & Doğu Akdeniz Elementi & -1 & Boğumluçay & 3,4 \\
\hline & *Origanum laevigatum Boiss. & Doğu Akdeniz Elementi & -1 & Kır mercanı & 1 \\
\hline & O. onites L. & Doğu Akdeniz Elementi & -1 & Bilyalı kekik & $1,2,3$ \\
\hline & *Prunella vulgaris $\mathrm{L}$. & Avrupa-Sibirya Elementi & -1 & Gelincikleme otu & 3,4 \\
\hline & Salvia fruticosa Mill. & Doğu Akdeniz Elementi & -1 & Adaçayı & 1 \\
\hline & S. verbenaca L. & Akdeniz Elementi & -1 & Elma kekiği & 3 \\
\hline & ${ }^{*} S$. viridis $\mathrm{L}$. & Akdeniz Elementi & -1 & Zarifşalba & $2,3,4$ \\
\hline & *Stachys amanica P.H.Davis & Doğu Akdeniz Elementi & $+/ \mathrm{NT}$ & Kalın karabaş & 1 \\
\hline & S. rupestris Montbret \& Aucher ex Benth. & Doğu Akdeniz Elementi & $+/ \mathrm{LC}$ & Bodur deliçay & 2,4 \\
\hline & Vitex agnus-castus L. & Akdeniz Elementi & $-/$ & Hayıt & 3,4 \\
\hline Lauraceae & Laurus nobilis L. & Akdeniz Elementi & -1 & Defne & $2,3,4$ \\
\hline Linaceae & $\begin{array}{l}\text { Linum hirsutum L. subsp. pseudoanatolicum } \\
\text { P.H.Davis }\end{array}$ & İran-Turan Elementi & $+/ \mathrm{LC}$ & Bozkır keteni & 1,2 \\
\hline Lythraceae & Punica granatum $\mathrm{L}$. & - & -1 & Nar & $1,2,4$ \\
\hline \multirow[t]{2}{*}{ Malvaceae } & Alcea digitata (Boiss.) Alef. & İran-Turan Elementi & -1 & Boylu hatmi & 1 \\
\hline & Malva sylvestris L. & - & -1 & Ebegümeci & 1,4 \\
\hline \multirow{2}{*}{ Moraceae } & Ficus carica L. subsp. carica & Geniş Yayılışlı & -1 & İncir & $1,2,3,4$ \\
\hline & Morus alba L. & Geniş Yayıllışlı & -1 & Akdut & 1 \\
\hline Myrtaceae & Myrtus communis L. subsp. communis & - & -1 & Mersin & 2,3 \\
\hline \multirow[t]{6}{*}{ Oleaceae } & Fontanesia philliraeoides Labill. & Doğu Akdeniz Elementi & $-/$ & Cilbirtı & $2,3,4$ \\
\hline & Fraxinus ornus L. subsp. cilicica & Doğu Akdeniz Elementi & $+/ \mathrm{LC}$ & Toros dişbudağı & 1,3 \\
\hline & Jasminum fruticans L. & Akdeniz Elementi & $-/$ & Boruk & $1,2,3$ \\
\hline & Olea europaea L. & - & -1 & Zeytin & 2 \\
\hline & O. europaea L. subsp. europaea & Akdeniz Elementi & -1 & Zeytin & 3 \\
\hline & ${ }^{*}$ Phillyrea latifolia $\mathrm{L}$. & Akdeniz Elementi & -1 & Akçakesme & $2,3,4$ \\
\hline Orchidaceae & Ophrys speculum Link subsp. speculum & Akdeniz Elementi & $-/$ & Ayna salebi & 3 \\
\hline \multirow{2}{*}{ Papaveraceae } & Papaver rhoeas L. & Geniş Yayılışlı & -1 & Gelincik & 1,2 \\
\hline & P. syriacum Boiss. \& Blanche & - & $-/$ & Kellinar & 2 \\
\hline \multirow[t]{2}{*}{ Pinaceae } & Pinus brutia Ten. & Doğu Akdeniz Elementi & -1 & Kızılçam & 2,3 \\
\hline & P. pinea $\mathrm{L}$. & GenişYayılışlı & -1 & Fistık çamı & 2 \\
\hline \multirow[t]{4}{*}{ Plantaginaceae } & Anarrhinum orientale Benth. & İran-Turan Elementi & -1 & Süpürge otu & 1 \\
\hline & Plantago lanceolata $\mathrm{L}$. & Geniş Yayılışlı & -1 & Damarlica & 3 \\
\hline & P. major L. subsp. major & - & -1 & Sinir otu & 4 \\
\hline & Veronica kotschyana Benth. & Doğu Akdeniz Elementi & $+/ \mathrm{NT}$ & Kaya mavişi & 1 \\
\hline Platanaceae & Platanus orientalis $\mathrm{L}$. & Geniş Yayılışlı & $-/$ & Çınar & $2,3,4$ \\
\hline \multirow[t]{6}{*}{ Poaceae } & Arundo donax $\mathrm{L}$. & - & $-/$ & Karg1 & 3 \\
\hline & $\begin{array}{l}\text { Avena sterilis L. subsp. ludoviciana (Durieu) } \\
\text { Gillet et Magne }\end{array}$ & - & -1 & Horazotu & 1 \\
\hline & Dactylis glomerata L. subsp. glomerata & Avrupa-Sibirya Elementi & -1 & Domuzayrı̆̆ı & $1,2,3$ \\
\hline & Hordeum bulbosum L. & Geniş Yayılışlı & -1 & Boncuk arpa & 1 \\
\hline & Pennisetum orientale Rich. & İran-Turan Elementi & -1 & Fiskiye otu & 3 \\
\hline & Phragmites australis (Cav.) Trin. ex Steud. & Avrupa-Sibirya Elementi & -1 & Kamiş & 3 \\
\hline Polygonaceae & Rumex crispus L. & - & -1 & Labada & 4 \\
\hline Pteridaceae & Adiantum capillus-veneris L. & Geniş Yayılışlı & -1 & Baldırıkara & 2,4 \\
\hline \multirow[t]{2}{*}{ Ranunculaceae } & ${ }^{*}$ Thalictrum orientale Boiss. & Doğu Akdeniz Elementi & -1 & Zarif kaytaran & 2 \\
\hline & ${ }^{*}$ Clematis cirrhosa $\mathrm{L}$. & Akdeniz Elementi & -1 & Bahar sarmaşı̆̆ı & 3 \\
\hline Rhamnaceae & Paliurus spina-christi Mill. & - & -1 & Karaçalı & $1,3,4$ \\
\hline \multirow[t]{7}{*}{ Rosaceae } & Crataegus monogyna Jacq. var. monogyna & Geniş Yayılışlı & $-/$ & Yemişen & 3,4 \\
\hline & Geum urbanum L. & Avrupa-Sibirya Elementi & -1 & Meryem otu & 1 \\
\hline & *Potentilla calycina Boiss. and Balansa & DoğuAkdeniz Elementi & $+/ \mathrm{LC}$ & İçel parmakotu & 1 \\
\hline & Pyracantha coccinea M.Roem. & - & -1 & Ateş dikeni & 4 \\
\hline & Rosa canina $\mathrm{L}$. & - & -1 & Kuşburnu & 1 \\
\hline & Rubus sanctus Schreb. & Geniş Yayılışlı & -1 & Böğürtlen & $1,2,3,4$ \\
\hline & Sanguisorba minor Scop. subsp. minor & Geniş Yayılışlı & -1 & Çayır düğmesi & 1 \\
\hline Smilaceae & *Smilax aspera $\mathrm{L}$. & - & -1 & Gıcır Dikeni & $1,2,3,4$ \\
\hline Styracaceae & Styrax officinalis L. & - & -1 & Ayıfındığı & $1,3,4$ \\
\hline Tamaricaceae & Tamarix smymensis Bunge & - & -1 & Ilgın & 3 \\
\hline Ulmaceae & Ulmus glabra Huds. & Avrupa-Sibirya Elementi & $-/$ & Dağ karağacı & 1 \\
\hline Urticaceae & *Parietaria judaica L. & Geniş Yayıllışlı & -1 & Duvar fesleğeni & 2,4 \\
\hline Verbenaceae & Verbena officinalis L. & Geniş Yayılışlı & -1 & Mineçiçeği & 2 \\
\hline Vitaceae & Vitis vinifera $\mathrm{L}$. & - & -1 & Asma & 1,2 \\
\hline
\end{tabular}

Araştırma alanı ve yakın bölgelerde yapılan floristik çalışmalarda tespit edilen endemizm oranları bakımından bir karşılaştırma yapıldığında, en yüksek endemizm oranının \%24.38 ile Osmaniye Doğa Turizmi Master Planı çalışmasında, en düşük oranının ise \%1.3 ile Adana
Yumurtalık Lagününde sinda olduğu görülmüştür (Orman ve Su Işleri Bakanlığı, 2013; Altınözlü, 2004). Osmaniye Doğa Turizmi Master Planı adlı çalışmada endemizm oranının yüksek çıkması, bölgenin yükselti ve habitat bakımından çok çeşitliliğe sahip olmasıyla açılanabilir (Tablo 3). 
Araştırma alanları ile yakın bölgelerde yapılan floristik çalışmalarda tespit edilen taksonlar, fitocoğrafik bölgelere göre dağılımı bakımından kıyaslandığında Sarımsak Dağı ve Korkun Vadisi adlı çalışma hariç diğer çalışmalarda Akdeniz fitocoğrafik bölge elementinin yüksek olduğu görülmüştür (Altınözlü, 2004; Kavak, 2006; Akınc1, 2010; Paksoy, \& Savran, 2011; Kavak et al., 2012; Orman ve Su İşleri Bakanlığı, 2013; Keskin, 2014). Bu durum, söz konusu alanların Akdeniz bölgesinde yer alması şeklinde açıklanabilir (Tablo 4).

Araştırma alanları ile yakın bölgelerinde yapılan floristik çalışmalar, en çok takson içeren familyalar bakımından kıyaslandığında Adana Yumurtalık Lagünü, Burnaz Kumulları ve Osmaniye Doğa Turizmi Master Planı adlı çalışmalarda Fabaceae familyasının ilk sırada, diğer tüm çalışmalarda ise Asteraceae familyasının ilk sırada yer aldığı görülmüştür (Altınözlü, 2004; Kavak, 2006; Akınc1, 2010; Paksoy \& Savran, 2011; Kavak et al., 2012; Orman ve Su İşleri Bakanlığı, 2013; Keskin, 2014). İlk iki sırada çıan Fabaceae ve Asteraceae familyaları Davis (1965-1985)'e göre içerdikleri takson sayıları bakımından yine ilk iki sırada bulunmaktadır (Tablo 5).

Araştırma alanları ile yakın bölgelerde yapılan floristik çalışmalar en çok takson içeren cinsler bakımından kıyaslandığında, araştırma alanında ilk dört sirada 3 taksonla Securigera DC., Centaurea L., Quercus L. ve Salvia L. cinsleri yer almaktadır. Bu cinslere ait takson sayıları, yakın bölgelerde yapılan floristik çalışmalarda tespit edilen cinslere ait takson sayısına göre nispeten benzerlik göstermektedir (Altınözlü, 2004; Kavak, 2006; Akınc1, 2010; Paksoy \& Savran, 2011; Orman ve Su İşleri Bakanlığı, 2013; Keskin, 2014). Tatarlı Höyük (Kavak et al., 2012) çalışmasında ilk 4 sırada yer alan cinslerin herhangi bir benzerlik göstermemesi habitat farklılığı ve Höyük etrafında bulunan yerleşim alanlarının fazlalığ 1 ile açıklanabilir (Tablo 6). Araştırma alanlarımız korunan alan statüsünde (Sit Alanları) olduğundan floristik kompozisyonu tehdit eden herhangi bir olguya rastlanmamıştır.

Tablo 2. Araştırma alanında tespit edilen taksonların fitocoğrafik bölgelere göre dağılımları

\begin{tabular}{lcc}
\hline Fitocoğrafik Elementi & Takson Sayısı & Oranı \\
\hline Akdeniz & 63 & $\% 38.4$ \\
Avrupa-Sibirya & 10 & $\% 6.1$ \\
İran-Turan & 7 & $\% 4.3$ \\
Geniş Yayılışlı & 39 & $\% 23.8$ \\
Bilinmeyenler & 45 & $\% 27.4$ \\
\hline Toplam & 164 & $\% 100$ \\
\hline
\end{tabular}

Tablo 3. Araştırma alanı ve yakın bölgelerinde yapılan çalışmaların endemizm oranları

\begin{tabular}{clc}
\hline No & Araştırma Alanı & $\begin{array}{c}\text { Endemizm } \\
\text { Oranı }\end{array}$ \\
\hline 1 & Araştırma alanımız & $\% 9.1$ \\
2 & Adana Yumurtalık Lagünü (Altınözlü, 2004) & $\% 1.3$ \\
3 & Burnaz Kumulları (Kavak, 2006) & $\% 3.05$ \\
4 & Akdağ ve Çevresi (Akıncı, 2010) & $\% 13.6$ \\
5 & Sarımsak dağı ve Korkun Vadisi (Paksoy \& & $\% 20.7$ \\
6 & Savran, 2011) & $\% 2$ \\
7 & Tatarlı Höyük (Kavak et al., 2012) & $\% 24.38$ \\
8 & Osmaniye Doğa Turizmi Master Planı & $\% 16.8$ \\
\hline
\end{tabular}

Teșekkür: Bu çalışmanın bir kısmı ikinci yazar olan İshak ORTAÇ'in yüksek lisans çalışmasından ve Adıyaman Üniversitesine ait FEFYL-2016-0010nolu BAP projesi sonuç raporundan alınmıştır. Diğer kısmı ise T.C. Çevre ve Şehircilik Bakanlığının 2014/151078 nolu Ekolojik Temelli Bilimsel Araştırma Projesinden üretilmiştir. Maddi destekte bulunan her iki kuruma teşekkür ederiz.

Tablo 4. Araştırma alanı ve yakın bölgelerinde yapılan çalışmalardaki taksonların fitocoğrafik bölgelere dağılım oranları

\begin{tabular}{|c|c|c|c|c|c|}
\hline No & Araştırma Alanı & $\begin{array}{l}\text { Akdeniz } \\
\text { elementi }\end{array}$ & $\begin{array}{c}\begin{array}{c}\text { Avrupa-Sibirya } \\
\text { elementi }\end{array} \\
\end{array}$ & $\begin{array}{c}\text { İran-Turan } \\
\text { elementi }\end{array}$ & $\begin{array}{c}\text { Geniş Yayılışlı ve } \\
\text { bilinmeyenler }\end{array}$ \\
\hline 1 & Araştırma alanımız & $\% 38.4$ & $\% 6.1$ & $\% 4.3$ & $\% 51.2$ \\
\hline 2 & Adana Yumurtalık Lagünü (Altınözlü, 2004) & $\% 17.4$ & $\% 2.6$ & $\% 2.6$ & $\% 77.1$ \\
\hline 3 & Burnaz Kumulları (Kavak, 2006) & $\% 29.26$ & $\% 5.24$ & $\% 3.06$ & $\% 62.45$ \\
\hline 4 & Akdağ ve Çevresi (Akınc1, 2010) & $\% 19.4$ & $\% 5.1$ & $\% 16.9$ & $\% 58.6$ \\
\hline 5 & Sarımsak dağ1 ve Korkun Vadisi (Paksoy \& Savran, 2011) & $\% 18.9$ & $\% 3.45$ & $\% 24.6$ & $\% 53.05$ \\
\hline 6 & Tatarlı Höyük (Kavak et al., 2012) & $\% 33$ & $\% 5$ & $\% 3$ & $\% 59$ \\
\hline 7 & $\begin{array}{l}\text { Osmaniye Doğa Turizmi Master Planı (Orman ve Su İşleri Bakanlığı, } \\
\text { 2013) }\end{array}$ & - & - & - & - \\
\hline 8 & Kızıldağ Yayla ve Çevresi (Keskin, 2014) & $\% 18.8$ & $\% 4.1$ & $\% 17.2$ & $\% 59.9$ \\
\hline
\end{tabular}

Tablo 5. Araştırma alanı ve yakın bölgelerinde yapılan çalışmalarda en çok takson içeren familyalar

\begin{tabular}{|c|c|c|c|c|c|c|}
\hline No & Araştırma Alanı & Fabaceae & Asteraceae & Lamiaceae & Brassicaceae & Rosaceae \\
\hline 1 & Araştırma alanımız & 26 & 13 & 13 & 7 & 7 \\
\hline 2 & Adana Yumurtalık Lagünü (Altınözlü, 2004) & 41 & 26 & 7 & 6 & 3 \\
\hline 3 & Burnaz Kumulları (Kavak, 2006) & 48 & 27 & 5 & 7 & 2 \\
\hline 4 & Akdağ ve Çevresi (Akıncl, 2010) & 72 & 97 & 53 & 61 & 19 \\
\hline 5 & Sarımsak dağı ve Korkun Vadisi (Paksoy \& Savran, 2011) & 70 & 82 & 46 & 51 & 17 \\
\hline 6 & Tatarlı Höyük (Kavak et al.,2012) & 13 & 23 & - & - & - \\
\hline 7 & $\begin{array}{l}\text { Osmaniye Doğa Turizmi Master Planı (Orman ve Su İşleri Bakanlı̆̆ı, 2013- } \\
\text { 2023) }\end{array}$ & 20 & 15 & 13 & 2 & 3 \\
\hline 8 & Kızıldağ Yayla ve Çevresi (Keskin, 2014) & 55 & 67 & 44 & 54 & 28 \\
\hline
\end{tabular}


Tablo 6. Araştırma alanı ve yakın bölgelerinde yapılan çalışmalarda en çok takson içeren cinsler

\begin{tabular}{|c|c|c|c|c|c|}
\hline No & Araştırma Alanı & Securigera & Centaurea & Quercus & Salvia \\
\hline 1 & Araştırma alanımız & 3 & 3 & 3 & 3 \\
\hline 2 & Adana Yumurtalık Lagünü (Altınözlü, 2004) & 1 & 1 & 1 & 2 \\
\hline 3 & Burnaz Kumulları (Kavak, 2006) & - & 1 & - & 1 \\
\hline 4 & Akdağ ve Çevresi (Akıncı, 2010) & 3 & 9 & 5 & 13 \\
\hline 5 & Sarımsak dağı ve Korkun Vadisi (Paksoy \& Savran, 2011) & 2 & 12 & 4 & 14 \\
\hline 6 & Tatarlı Höyük (Kavak et al., 2012) & - & - & - & - \\
\hline 7 & Osmaniye Doğa Turizmi Master Planı (Orman ve Su İşleri Bakanlığı, 2013-2023) & 1 & 6 & 2 & 2 \\
\hline 8 & Kızıldağ Yayla ve Çevresi (Keskin, 2014) & 3 & 7 & 1 & 10 \\
\hline
\end{tabular}

\section{References}

Akıncı, H. (2010). Akdağ (Pozantı-Adana) ve Çevresinin Florası (Yüksek Lisans Tezi), Niğde Üniversitesi, Niğde, Türkiye.

Altınözlü, H. (2004). Flora of the Natural Conservation Area in AdanaYumurtalık Lagoon (Turkey). Tubitak, 28, 491-506.

Çevre ve Şehircilik Bakanlığı (2016). Adana, Hatay, Mersin, Kahramanmaraş, Osmaniye, Gaziantep ve Kilis İlleri Doğal Sit Alanlarının Ekolojik Temelli Bilimsel Araştırma Projesi (BAP), Yayınlanmamış Rapor (Proje No: 2014/151078), Ankara, Türkiye.

Davis, P.H., \& Hedge, I.C. (1975). Flora of Turkey Past, Present and Future, Candollea, Edinburgh, UK.

Davis, P.H. (1965-1985). Flora of Turkey and the East Aegean Islands. Vol.19, Edinburgh, Edinburgh University Press., UK.

Davis, P.H., Mill, R.R., \& Tan, K., (1988). Flora of Turkey and the East AegeanIslands. Vol.10, Edinburgh, Edinburgh University Press., 590 pp.

Güner A., Özhatay N., Ekim T., \& Başer K.H.C. (2000). Flora of Turkey and the East Aegean Islands, Vol. 11, Edinburgh, Edinburgh University Press., $656 \mathrm{pp}$.

Güner, A., Aslan, S., Ekim, T., Vural, M., Babaç, M.T. (2012). Türkiye Bitkileri Listesi (Damarlı Bitkiler). Nezahat Gökyiğit Botanik Bahçesi ve Flora A raştırmaları Derneği Yayını, İstanbul, 1290 pp.

Kavak, S. (2006). Burnaz Kumullarını (Adana) Flora ve Vejetasyonu (Yüksek Lisans Tezi), Çukurova Üniversitesi, Adana, Türkiye.

Kavak, S., Talip, Ö., Aslan, F., Çakan, H., \& Umut, Ş. (2012). Tatarlı Höyük (Ceyhan, Adana) Yüzey Florasının Etnobotaniksel Açıdan Değerlendirilmesi. 21. Ulusal Biyoloji Kongresi (pp. 142-143). İzmir, Türkiye, Ankamat matbaacillk, 1454 pp.

Keskin, A. (2014). Kızıldă̆ Yayla (Adana) ve Çevresinin Florası (Yüsek Lisans Tezi), Niğde Üniversitesi, Niğde, Türkiye.

Meteoroloji Genel Müdürlüğü (2019). İllere ait Mevsim normalleri (19812010) https://www.mgm.gov.tr/ veri değerlendirme/il-ve-ilçeler istatistik.aspx?m=OSMANIYE.

Orman ve Su İşleri Bakanlığı (2013). Osmaniye Doğa Turizmi Master Planı (2013-2023), Doğa Koruma ve Milli Parklar VII. Bölge Müdürlüğü, Osmaniye, Türkiye.

Ortaç, İ. (2017). Doğu Akdeniz Bölgesinde Bulunan Bazı Doğal ve Kültürel Sit Alanlarının Bitki Örtüsü Üzerine Araştırmalar (Yüksek Lisans Tezi), Adıyaman Üniversitesi, Adıyaman, Türkiye.

Paksoy, M.Y., \& Savran, A. (2011). The Flora of Sarımsak Mountain and Korkun Valley (Pozant1, Adana/Turkey), Biological Diversity and Conservation, 4(2), 155-171.

Vural M. (2006) Türkiye'nin Kırmızı Liste Taslağı, Retrieved from: http:// portal.milliparklar.gov.tr. 